\title{
الطبيعة القانونية للافتر العقاري وحجيته في إثبات الملكية العقارية الخاصة العفئة العقاري
}

The land register and its opposability in proving the ownership تاريخ الاستلام : 2019/09/12 ؛ تاريخ القبول : 2019/09/19

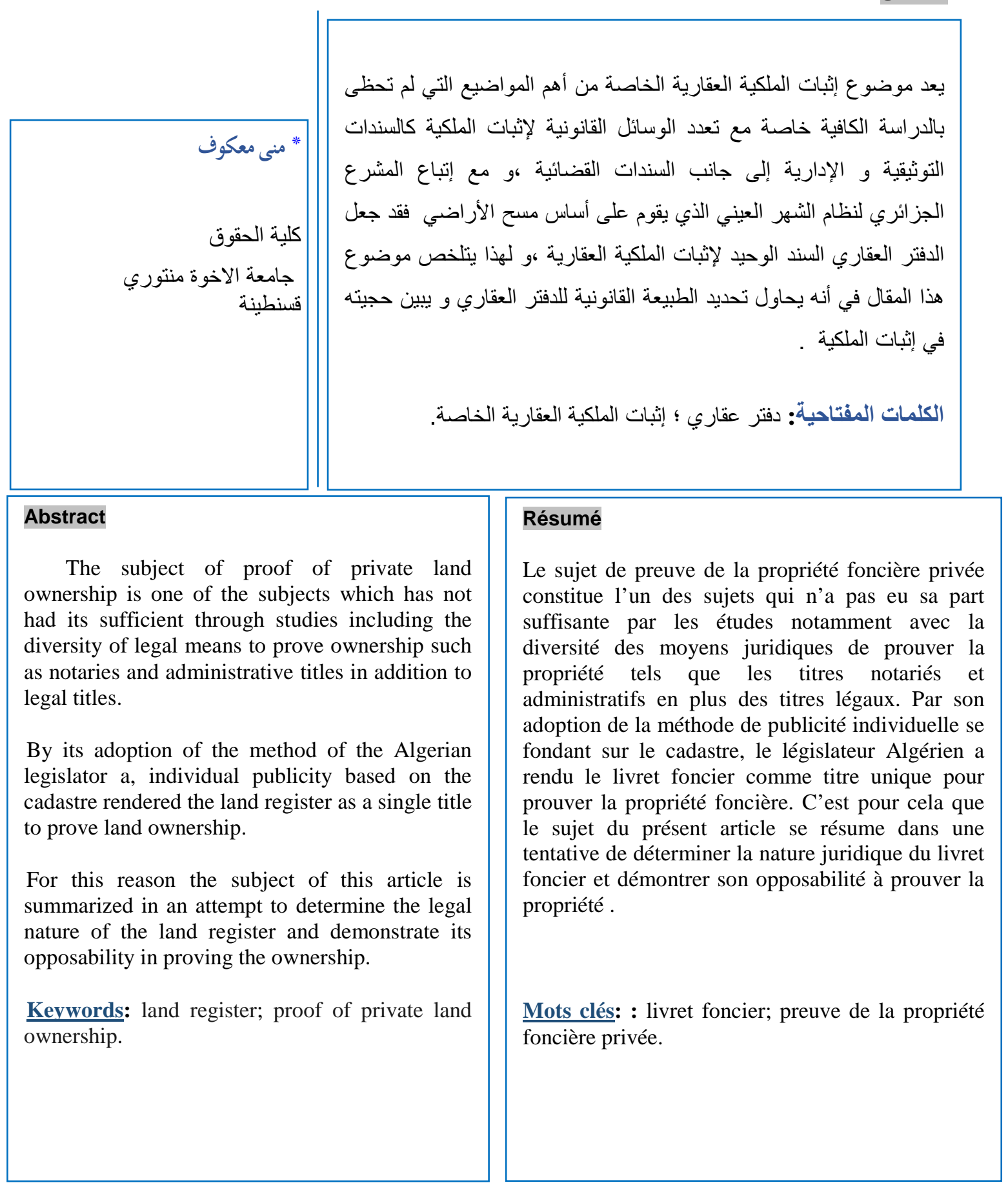

* Corresponding author, e-mail: makomouna@gmail.com 
I

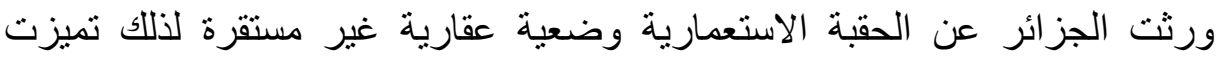

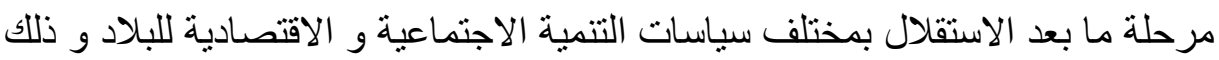

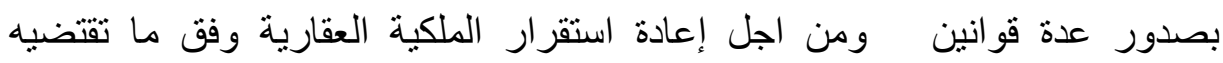

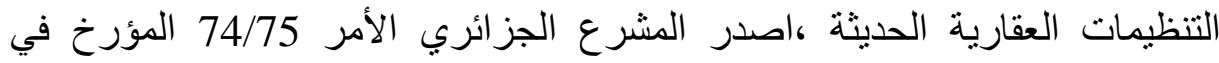

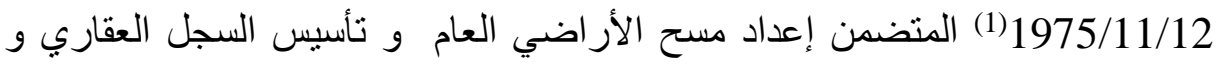

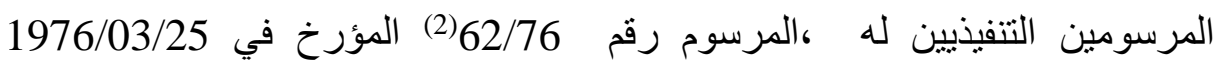

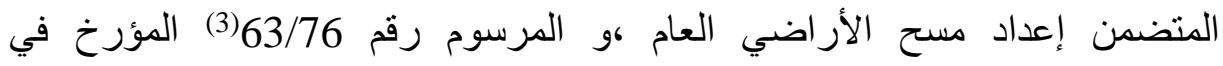

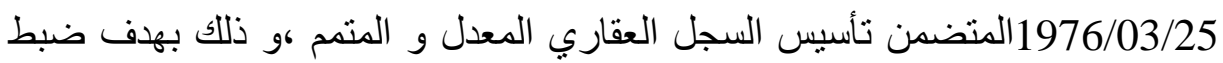

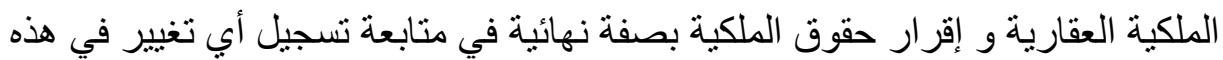

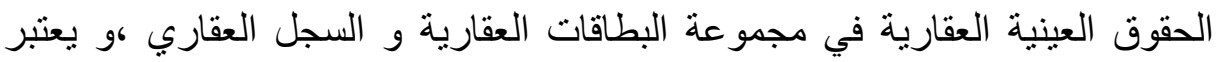

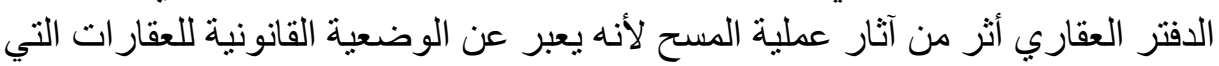

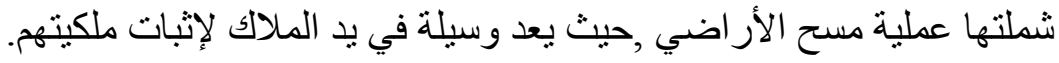
و على هذا الأساس فان الإراضي

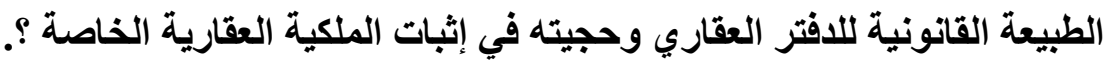

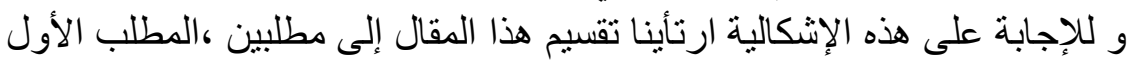

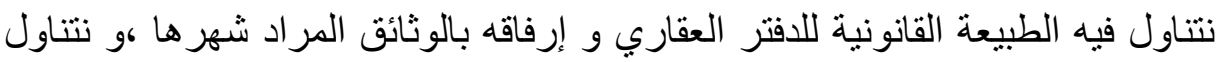

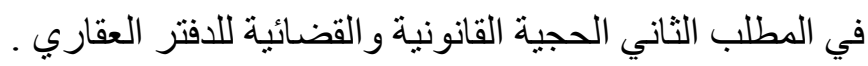

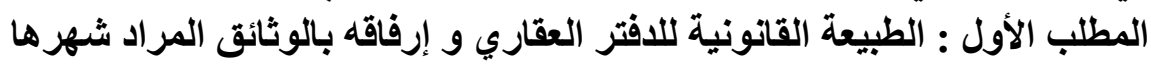

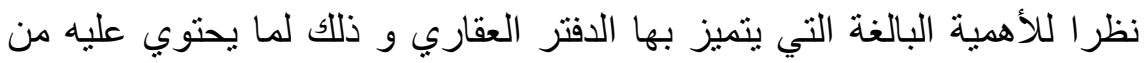

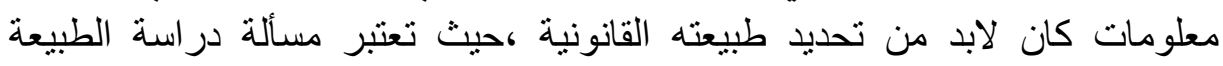

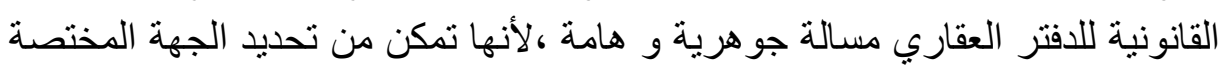

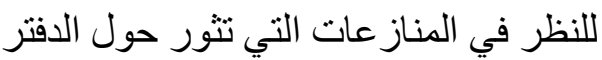

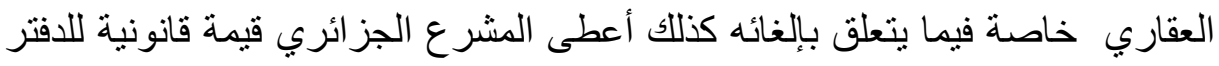

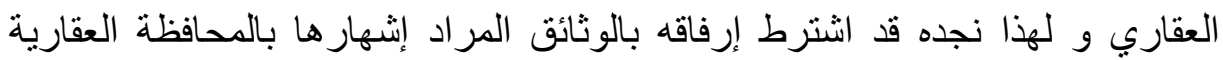

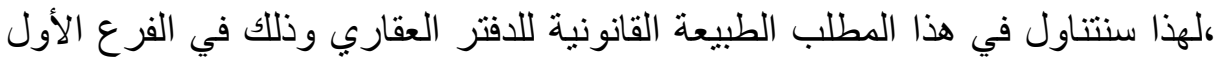

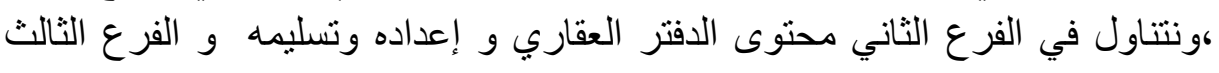

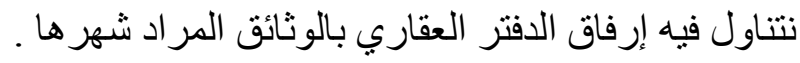

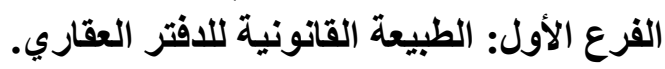

باعتبار أن الدفتر العقاري يصدر عن مصلحة إدارية عمومية الطارية تتمثل في المحافظة

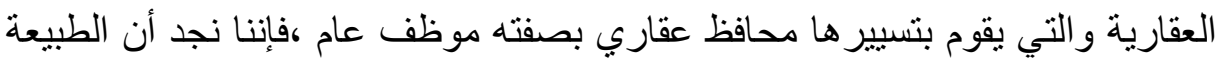

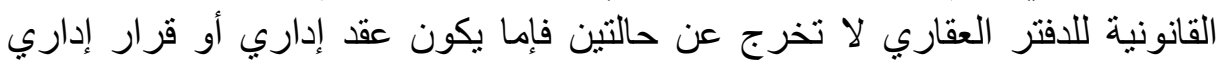

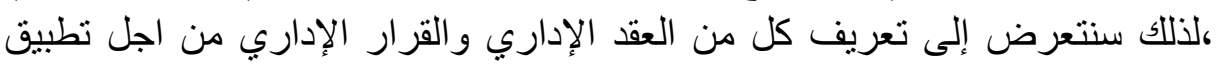

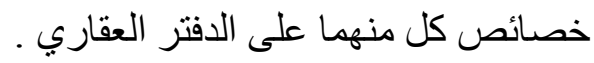
أولا : الدفتر العقاري عقد إداري.

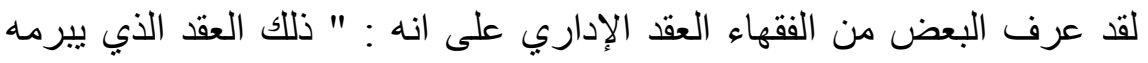

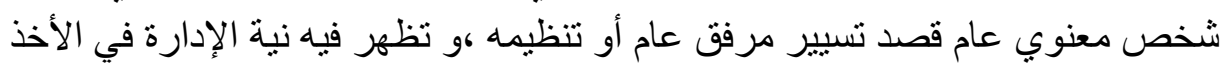


بأحكام القانون العام و ذلك أن يتضمن العقد شروط استثنائية غير مألوفة في القانون

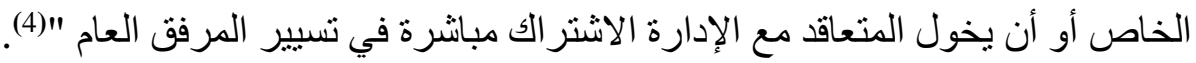

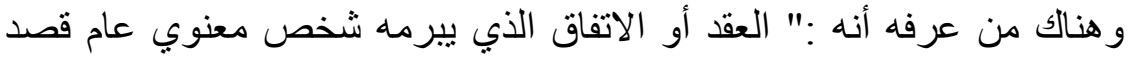

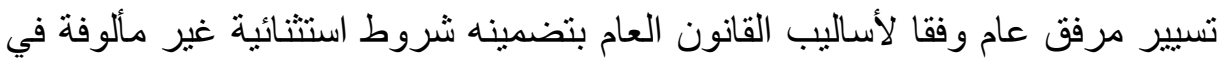
القانون الخاص "(5) . و هناك من عرفه على انه : "ذللك العقد الذي تكون الدولة أو الولاية أو البلدية أو

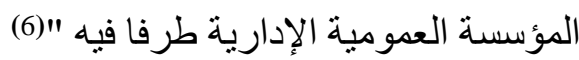
يتبين لنا من خلال هذه التعاريف أنه لكي نكون أمام عقد إداري بالمارية بالمعنى الدقيق

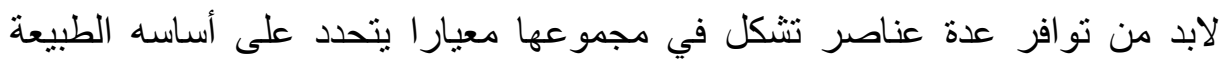

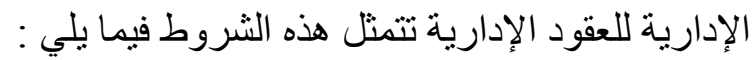

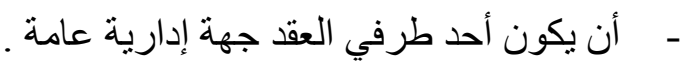
- - أن يرتبطو يتصل العقد بمرفق عام من حيث إدارته.

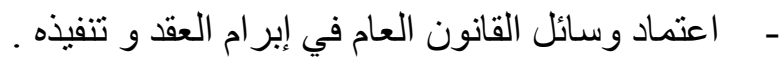

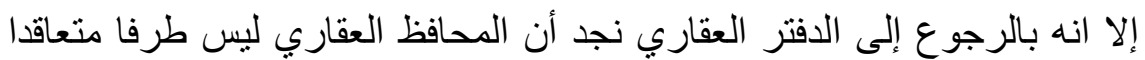

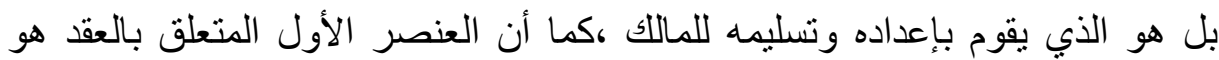

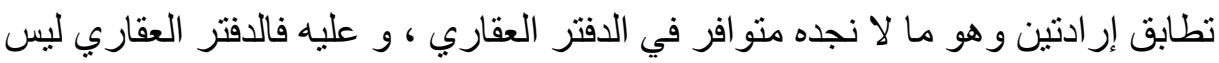
عقد إداري .

غير انه هناك من اعتبر الدفتر العقاري سند إثبات من الأسانيد التي أنتجها

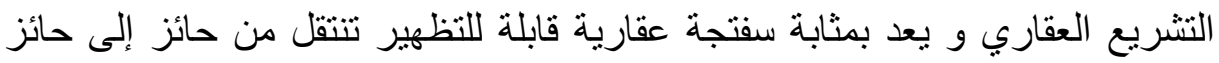

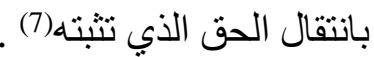
إلا أن ما يميزه انه مرتبط بمجموعة من القرار التهات الإدارية و هي :

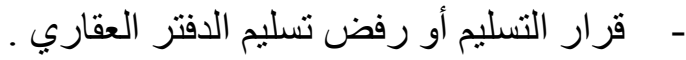

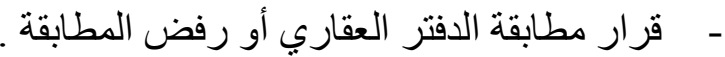

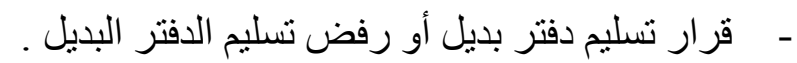

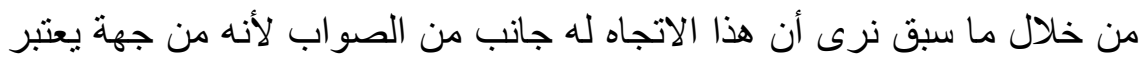

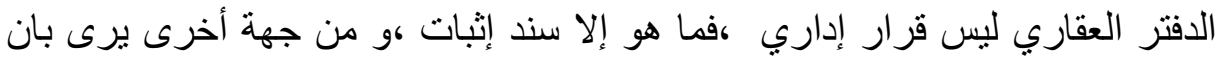

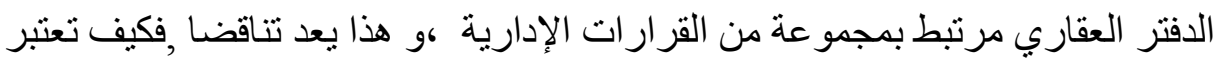

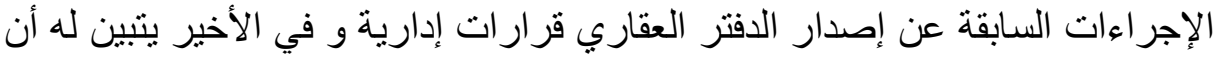
الدفتر العقاري ليس قرارا إداريا (8). ولللك نلاحظ أن الأسانيد التي اعتمدها هذا الإيات التجاه لتحديد الطبيعة القانونية للافتر

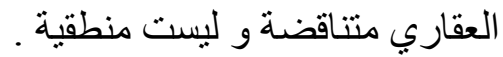
ثثاتيا : الافتر العقاري قرار إداري . لقد عرف بعض فقهاء العرب القرار الإداري العاري كما يلي : القرار الإداري هو:" عمل قانوني صادر بصفة إنبة انفر ادية من سلطة إدارية، الهدف منها هو إنشاء بالنسبة للغير حقوق و التزامات "(9)

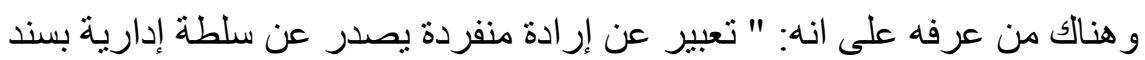
قانوني ،و يرتب آثار قانونية ،و يعتبر القرار الإداري أهم مظهر من مظاهر امتياز ات اتهرد 
السلطة العامة التي تتمتع بها الإدارة و تستمدها من القانون العام ،إذ بواسطته تنتطيع

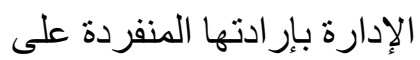

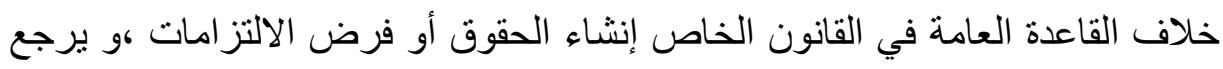

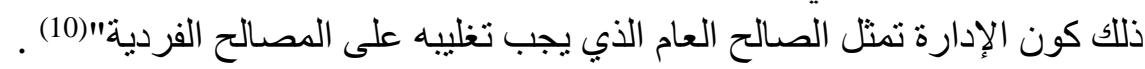

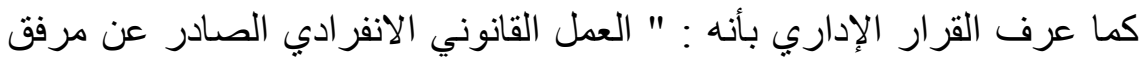

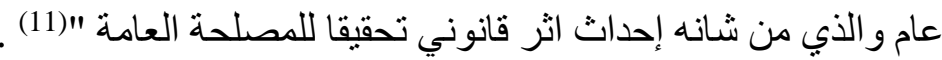

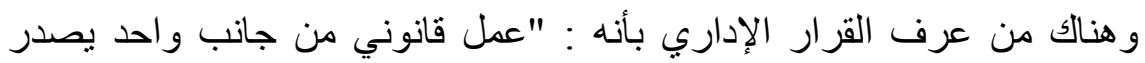

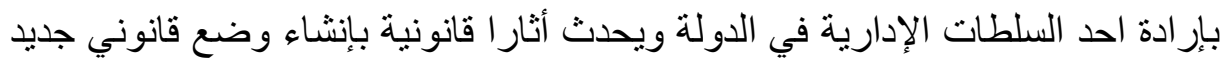
أو تعديل أو إلغاء وضع قانوني قائم "(12).

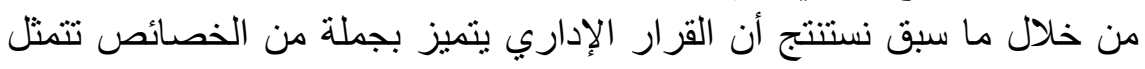
فيما يلي : 1- القرار الإداري تصرف : فانوني :

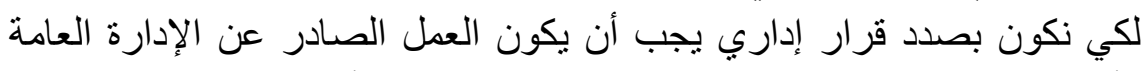

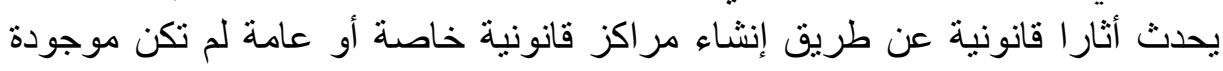

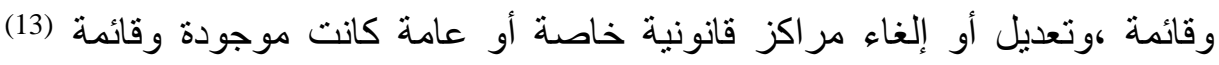

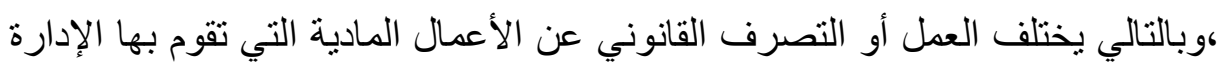

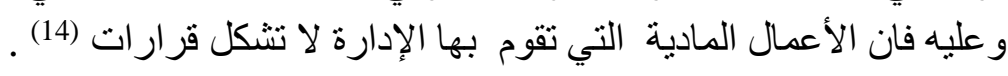

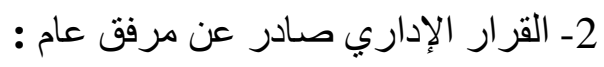

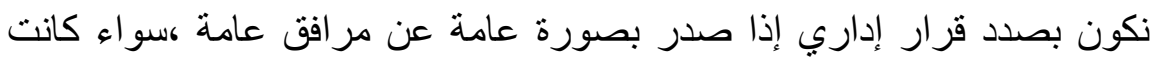

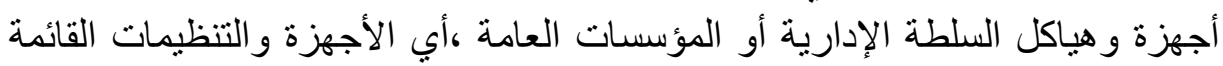

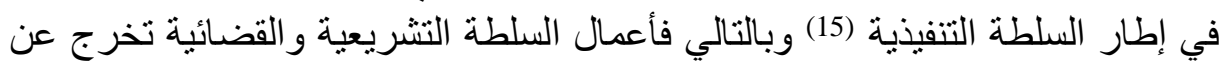

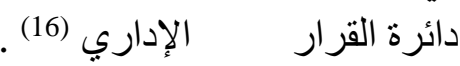
3 -القرار الإداري صادر بالإر ادة المنفردة :

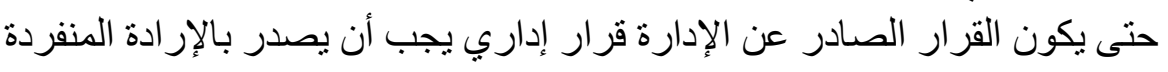

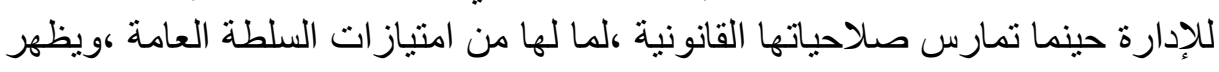

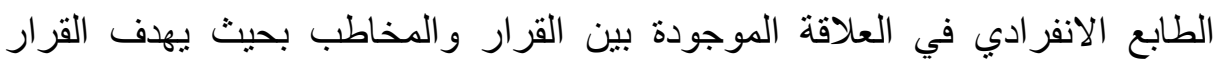

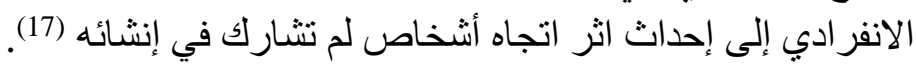

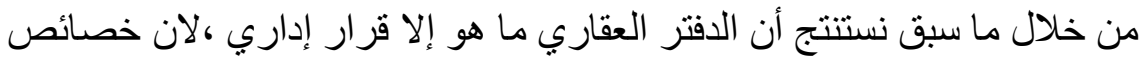
القرار الإداري تنطبق عليه ،حيث يخضع عند تحريره للشكل القانوني الذي حدده

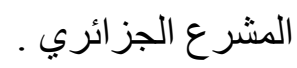

إضافة إلى ذلك انه يصدر عن هيئة إدارية هي المحافظة العقارية وبإرادتها المنفردة وهي مصلحة عمومية موضوعة تحت وصاية وز ارة المالية طبقا لنص المادة 2 من المرسوم التنفيذي 65/91 المؤرخ في 1991/3/2 المتضمن تنظيم المصالح الخارجية لأملاك الدولة و الحفظ العقاري(18) ،فبالر غم من تدخل هيئات أخرى ومساهمة بعض الأفراد في الأعمال التحضيرية لإعداد الدفتر العقاري والمتمنلة في المسح 
العقاري ،إلا انه ييقى متصف بالطابع الانفرادي ،وهذه المرحلة ما هي إلا مرحلة تحضيرية استوجبتها طبيعة الدفتر العقاري (19). ويقوم المحافظ العقاري بإعداده وتسليمه للمالك ،كما يحدث الدفتر العقاري أثنار إن قانونية لأنه بمجرد استلام المالك للافتر العقاري يصبح يتمتع بكافة صلاحيات التصرف والتمتع في عقاره كذلك لا يمكن الطعن فيه بالإلغاء إلا عن طريق القضاء

$$
\text { و هذا شان القرار الإداري . }
$$

و هذا ما ذهب إليه الأستاذ الدكتور عمار بوضياف و الأستاذ الدكتور مانع جمال

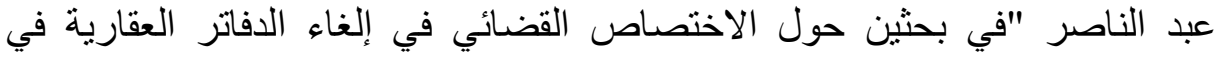

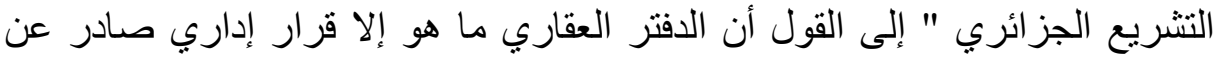

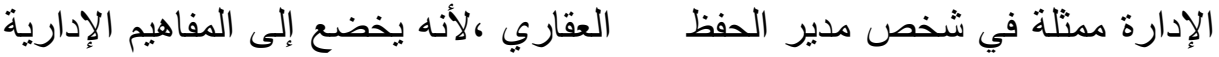

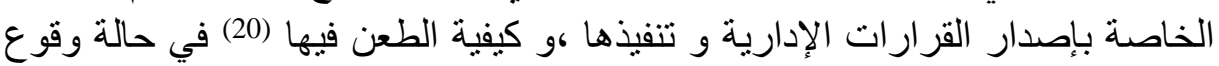

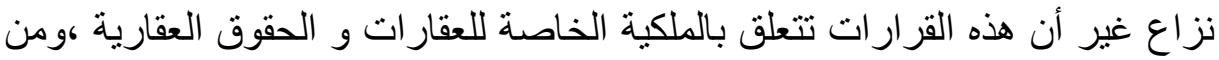

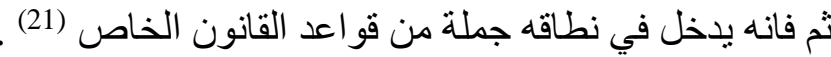

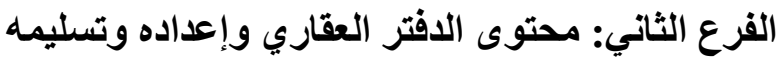

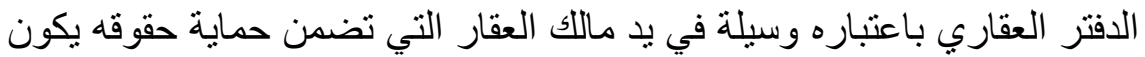

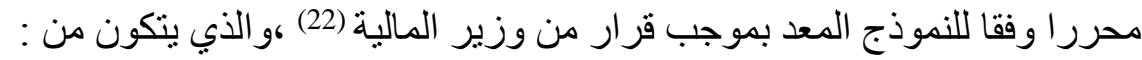

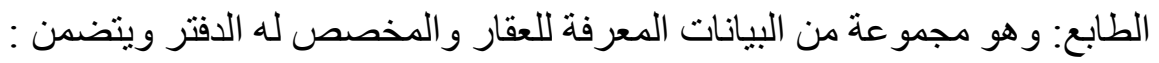

$$
\begin{aligned}
& \text { - } \\
& \text { - } \\
& \text { - رقم مجمو عة الملكية . }
\end{aligned}
$$

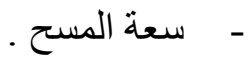

$$
\begin{aligned}
& \text { الجداول: وتحتوي على ما يلي : }
\end{aligned}
$$

الجدول الأول: الذي يوجد في الورقة الأولى ،يبين فيه مجمو عة الملكية مع ذكر النطاق

$$
\text { ( الموقع ، المساحة ،عدد القطع المكونة للملكية ). }
$$

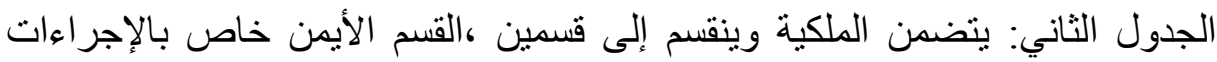
المتعلقة بالملكية أي تلك الإجراءات الأولية لنشهر الحقوق العقارية التهاية وكذا جميع التصرفات العقارية اللاحقة على العقار. الجدول الثالث :يتضمن قسمين ،القسم الأيمن ،تسجل فيه الارتفاقات العات الايجابية والسلبية

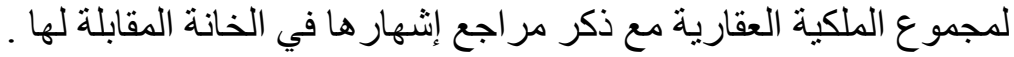
القسم الأيسر،تؤشر فيه جميع التغييرات أو التشطيبات التي قد تلحق بالحفر الحقوق المشهرة

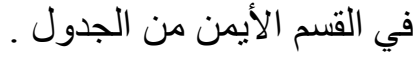
الجدول الرابع :يتضمن قسمين ،القسم الأيمن ،يحتوي على الحقوق المشهرة المتعلقة بالتجزئات و الأعباء . القسم الأيسر ،خاص بالتغييرات والتشطيبات الخاصة بالحقوق المشهرة في القسم

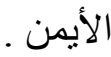
الجدول الخامس : يتضمن أيضا قسمين ،القسم الأيمن تؤشر فيه كل الامتيازات و 


$$
\text { الرهون التي تثتل الملكية العقارية . }
$$

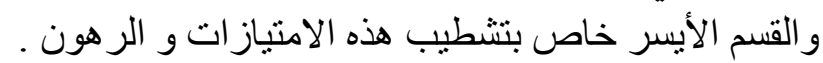

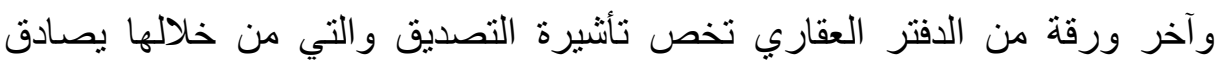
المحافظ العقاري

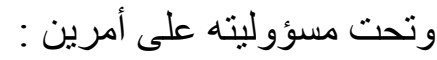
الأمر الأول : هو التصديق على على تاريخ تسليم هذا الدفتر للمالك .

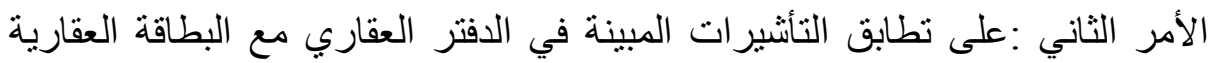

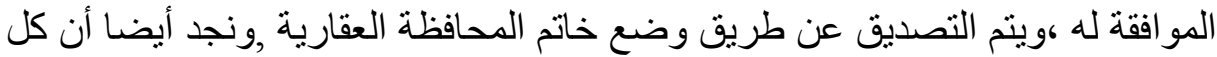

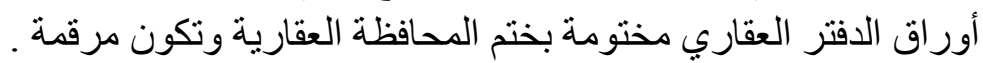

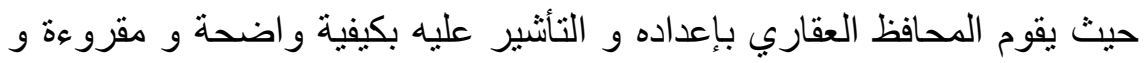

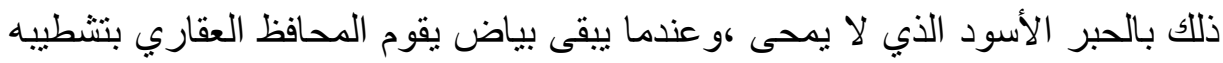

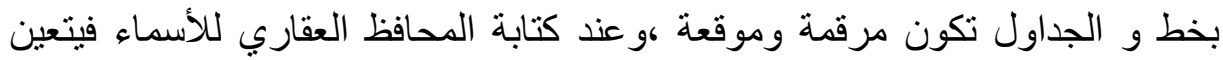

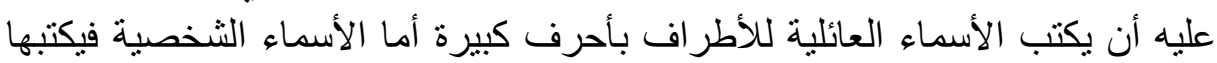

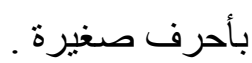

و يمنع عليه كذلك التحشير و الكثط أو السهو ،و يجب عليه وضع خط بعد كل عملية إجراء وذللك لتفادي الإضافات و التزوير ،و يتعين عليه كذلك و ضئ ضع تاريخ

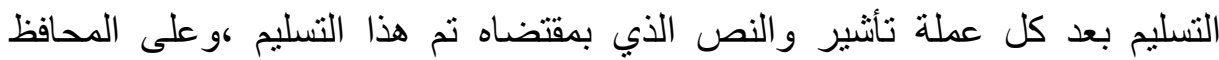

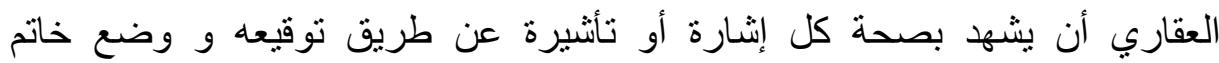

المحافظة(23)

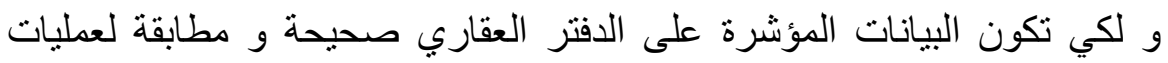

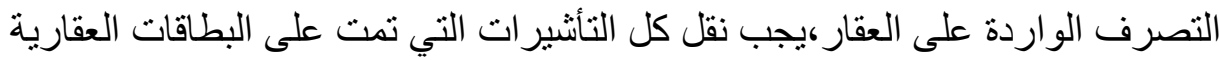

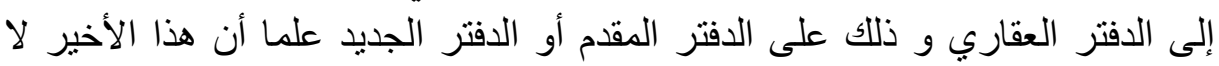

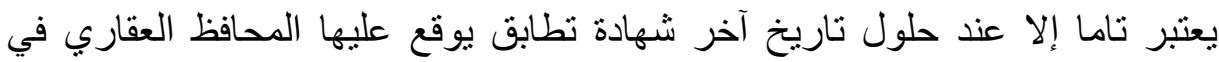

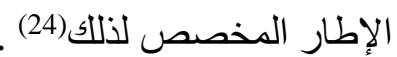

و بعد انتهاء المحافظ العقاري من إعداد الدفتر العقاري و ضبطه ،فانه يتم حفظه

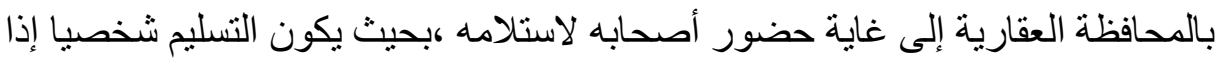

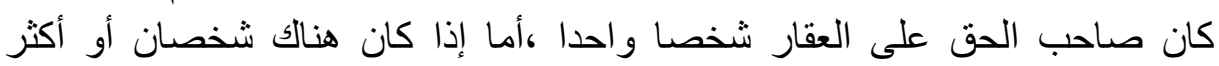

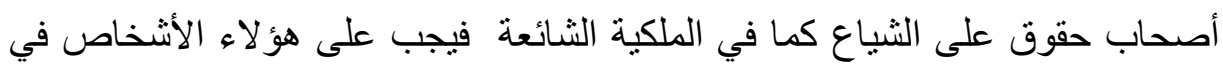

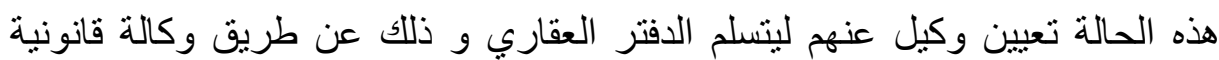

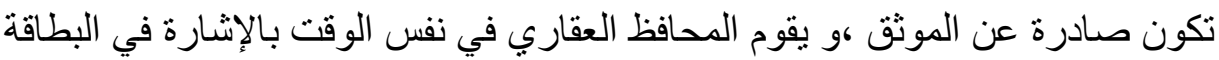

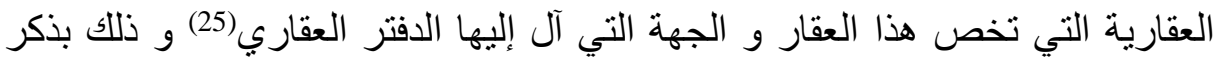

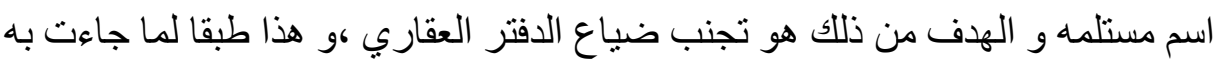

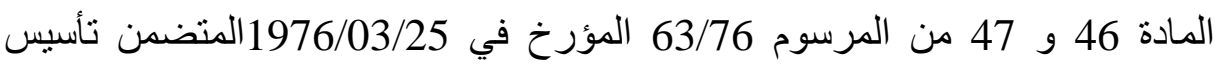
السجل العقاري ،بحيث انه عند التسليم الفعلي للافتر العقاري يؤشر فئر على البطاقة

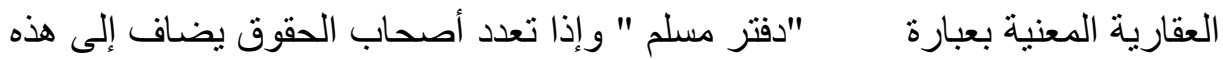
العبارة الجهة "الثخص" التي آل إليها الدفتر العقاري.

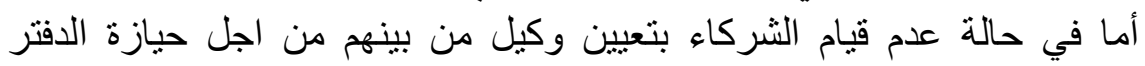

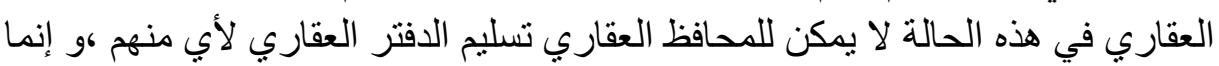


يقوم بالاحتفاظ بها في المحافظة العقارية .

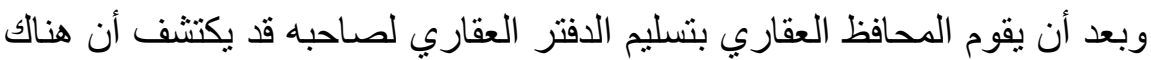

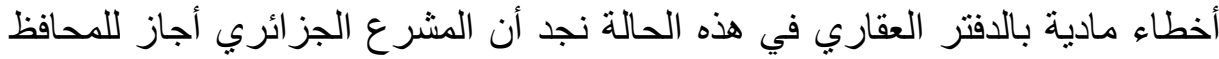

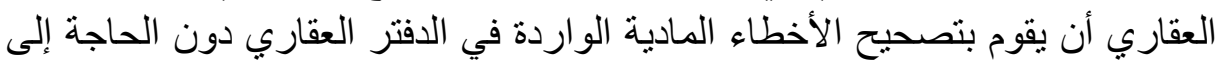

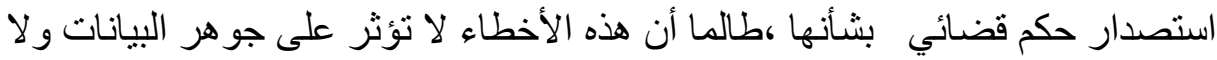

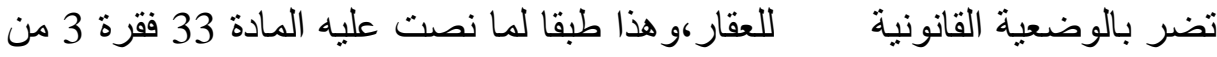

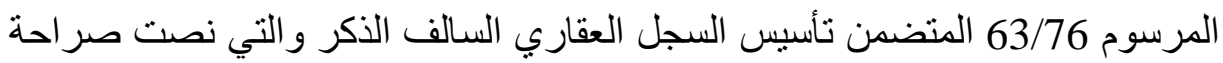

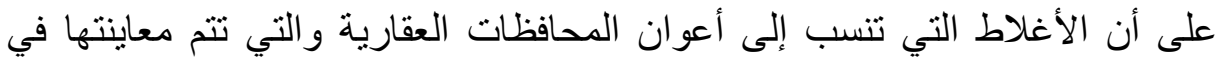
التأثنيرات على البطاقات العقارية يمكن تصحيحها(26) إما بمبادرة المحافظ العقارية العاري

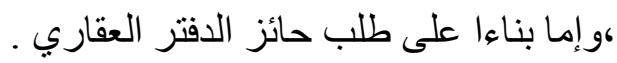
الحالة الأولى: التصحيح بمبادرة المحافظ العقاري

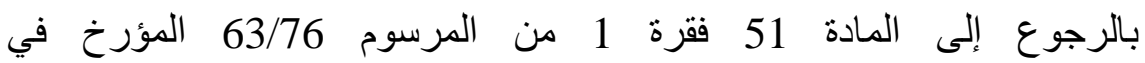
1976/3/25المتضمن تأسيس السجل العقاري نجدها نصت على على أن المحافظ العقاري

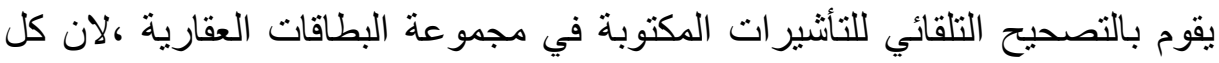

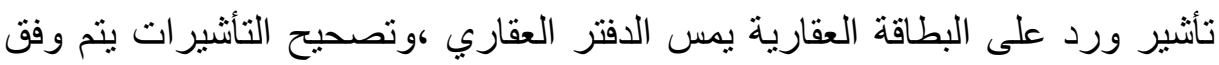
الخطوات التالية :

يقوم المحافظ العقاري بتبليغ المعنيين بهذا التصحيح ويقوم بتقديم إنذار إلى حائز الدفتر

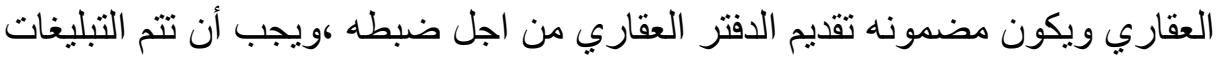

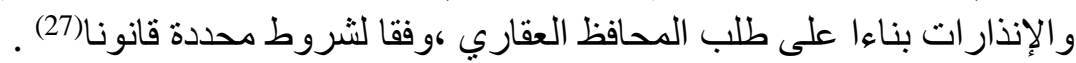

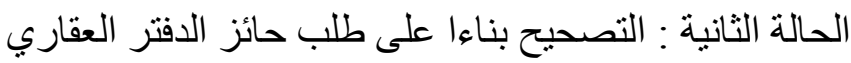

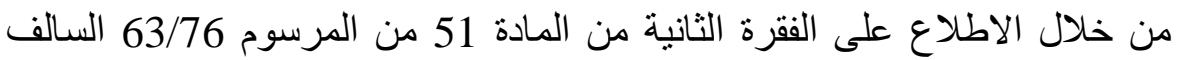

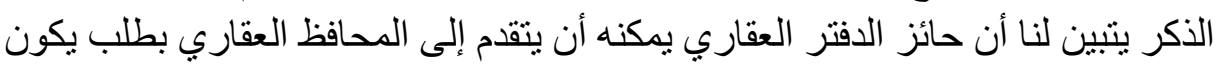

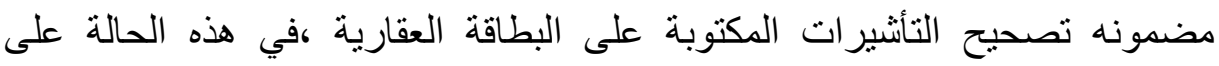

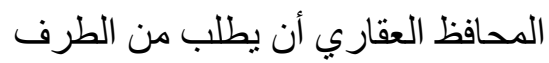

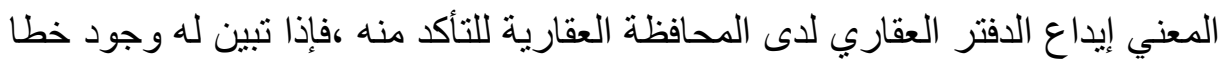

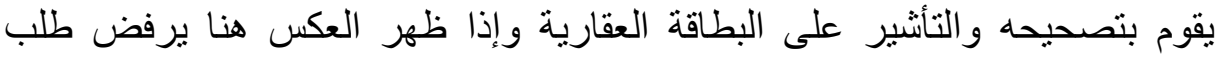

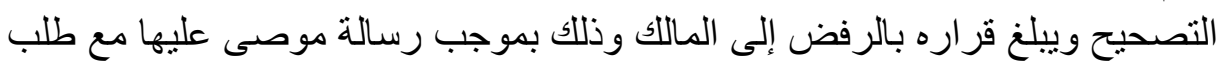

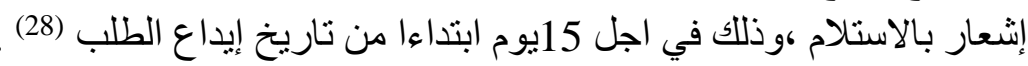

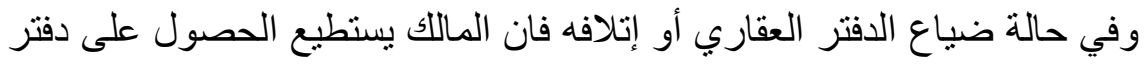

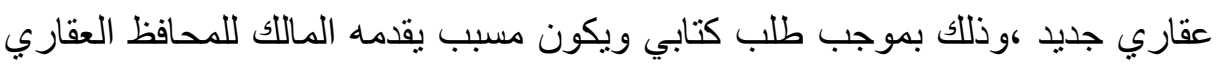

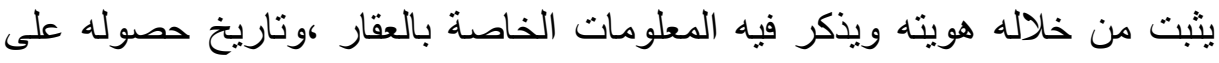

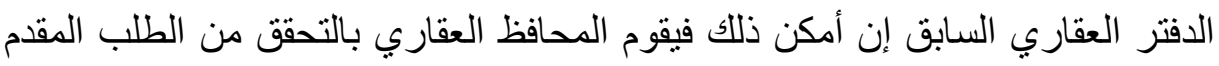

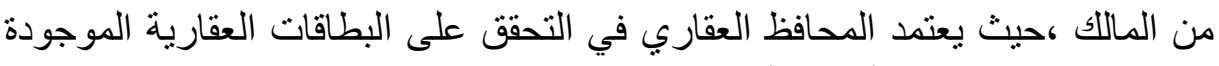

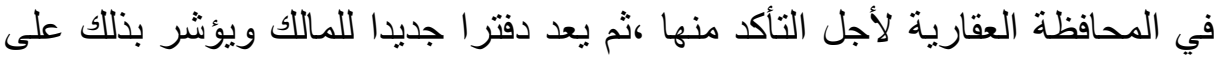

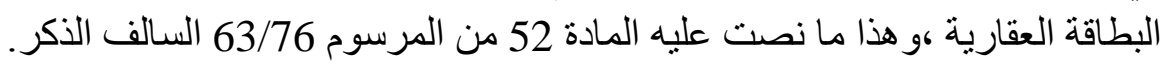

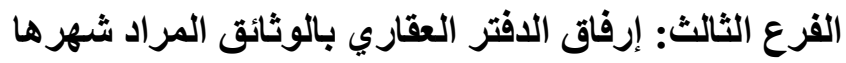

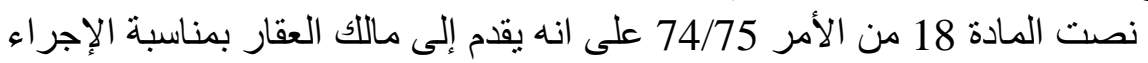

الأول دفتر عقاري تتسخ فيه البيانات الموجودة في مجمو عة البطاقات العقارية. وإن العقود الإدارية و الاتفاقات المشار إليها في المادة 16 من الأمر 


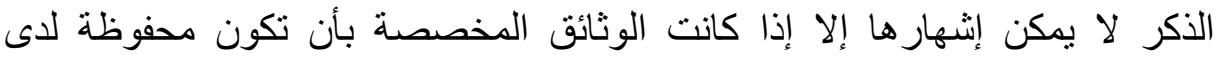

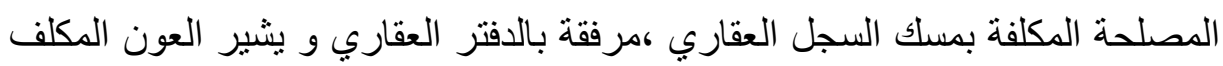

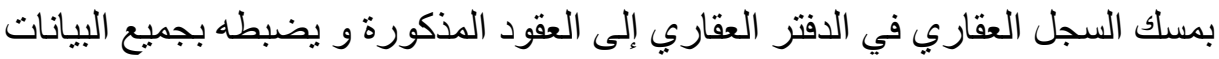
الموجودة في مجمو عة البطاقات العقارية.

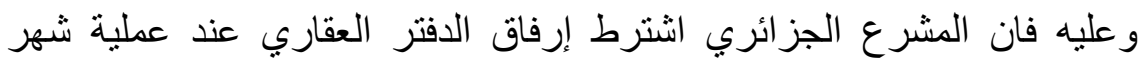

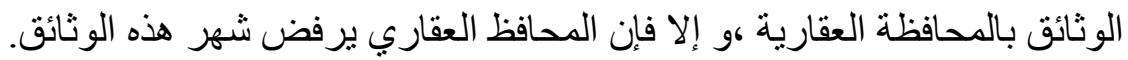

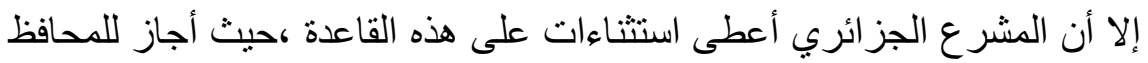

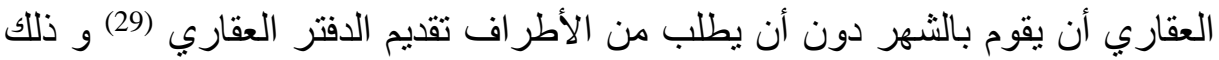

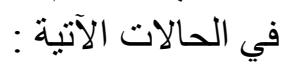

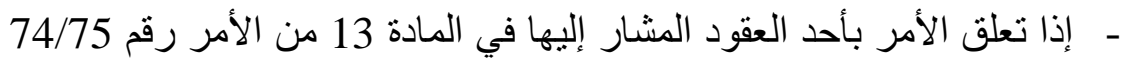
السالف الذكر و التي تشمل العقود التي تهرف إلى تأسيس مجمو عة البطاقات

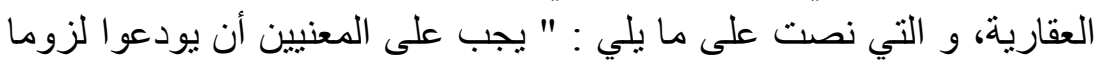

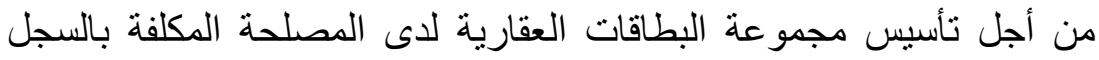

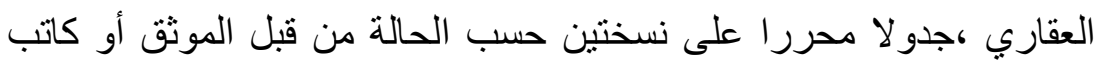

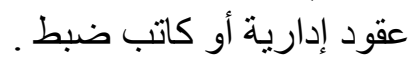

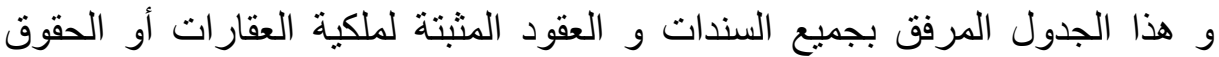

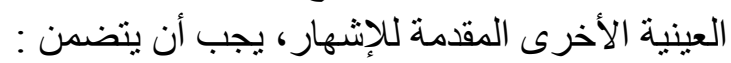

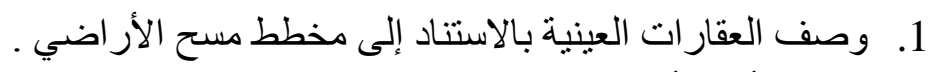
2. هوية و أهلية أصحاب الحقوق .

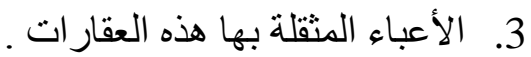

- بالعقود أو القرارات القضائية التي صدرت بدون مساعدة المالك أو التي صدرت - بتسجيل امتياز أو رهن قانوني أو قضائي . و عندما يقوم المحافظ العقاري بعملية الإشهار يقوم بتبليغه إلى حائز الدفتر

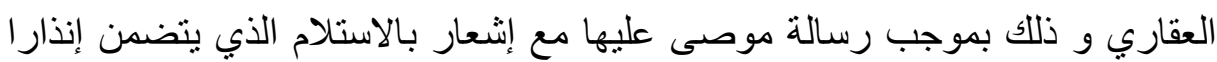

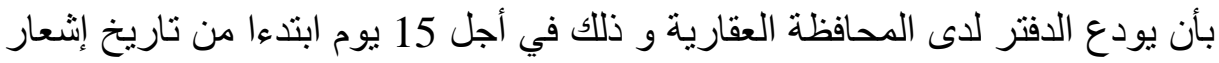

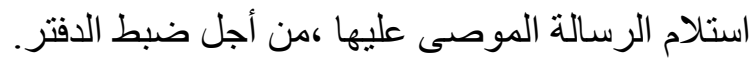

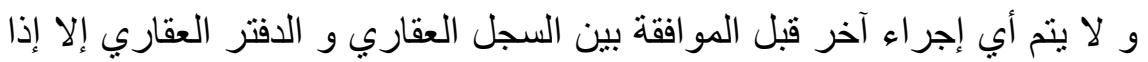

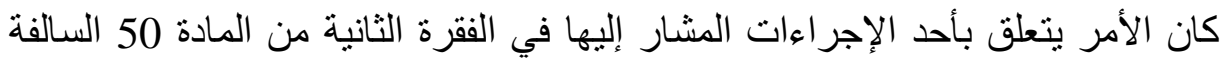
الذكر. و إذا بقي الإنذار بدون نتيجة وكان هناك نقل للملكية فإن المالك الجديد يمكنه أن يحصل النهل

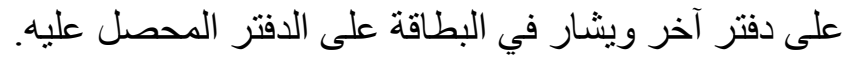

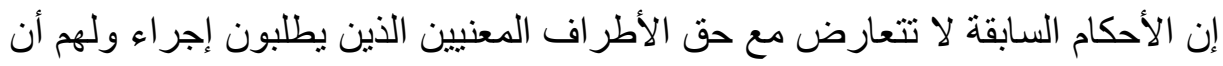

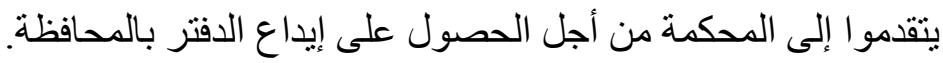

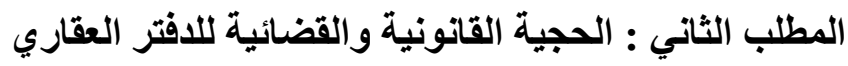

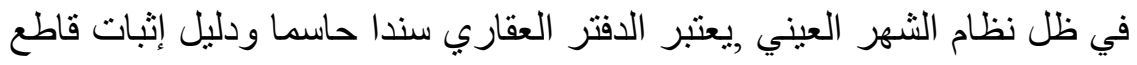

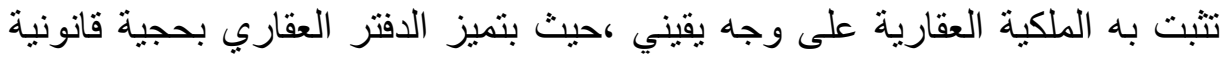

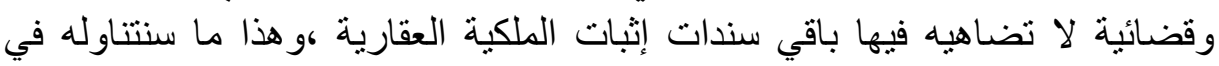


فرعين ،الفرع الأول نتناول فيه الحجية القانونية للافتر العقاري ،ونتناول في الفرع

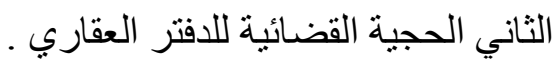
الفرع الأول : الحجية القانونية للافتر العقاري العاني

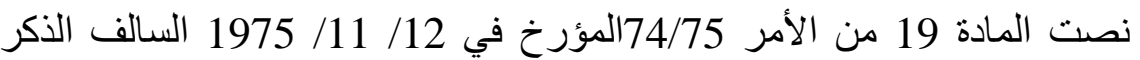

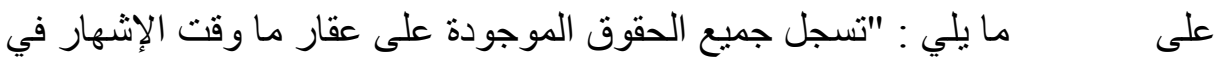
السجل العقاري في الدفتر الذي يشكل سند الملكية".

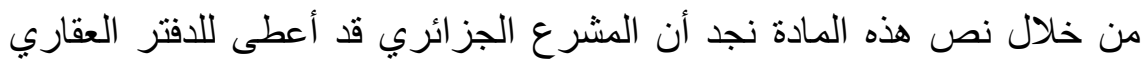

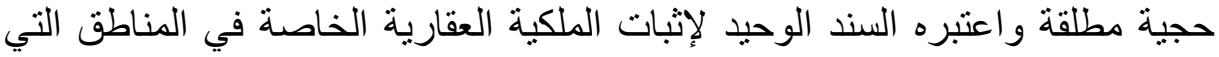

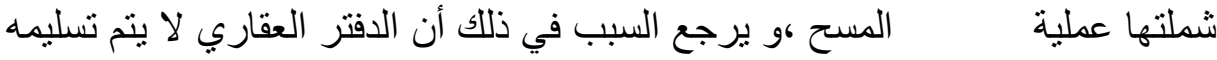

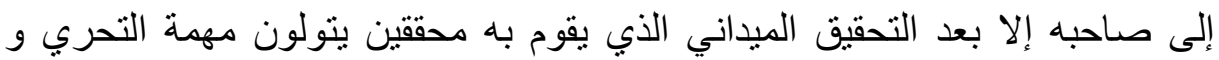
الاستقصاء على صحة البيانات المتعلقة بالعقار ات محل المسح وتحديدها بكيفية نافية

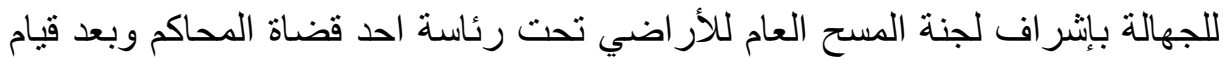

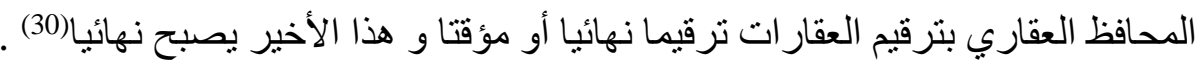

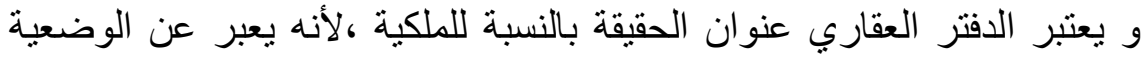

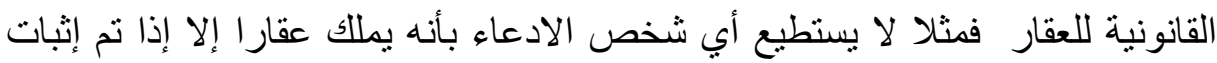
ادعائه بالدفتر العقاري ل العاري و هذا بالنسبة للعقار الممسوح ،وعليه فالدفتر العقاري يعد السند الوحيد الذي يثبت

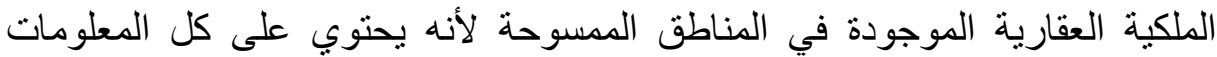
المتعلقة بالعقار وكل التصرفات القانونية الواردة عليه فهو بمثابة مرآة تعكس الحالة التهاية

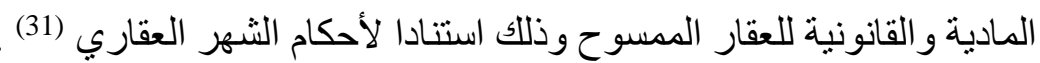

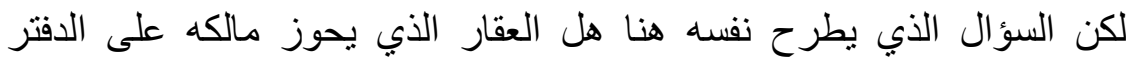

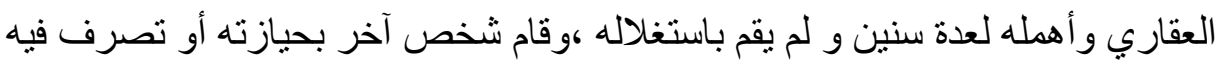

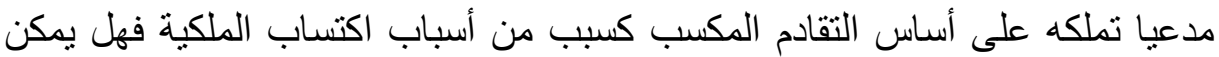

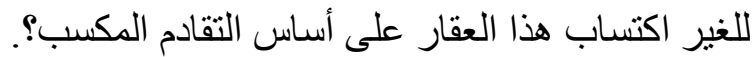

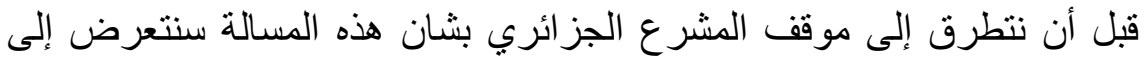

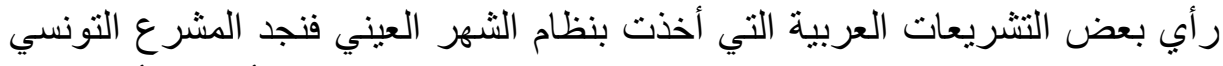
نص في الفصل 307 من قانون الثنهر العقاري على ما يلي :" ليس لأي كان أن يتمسك لئك بالحوز مهما طالت مدته ويختص حاكم الناحية بالحكم بكف الثغب ملثب الحاصل في الانتفاع

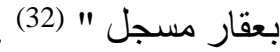
و هو نفس ما ذهب إليه المشرع المغربي الذي نص في الفصل 63 من قانون

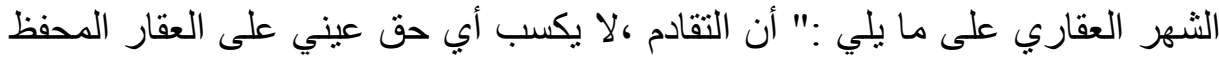

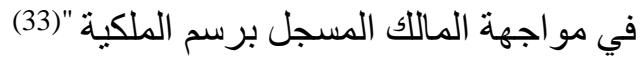

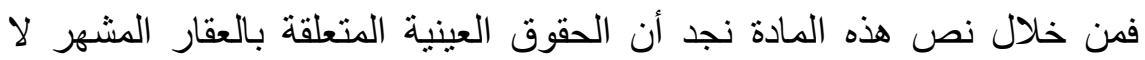
تكسب ولا تسقط بالتقادم ذلك أن قاعدة الحيازة سند الملكية لا يمكن تطبيقها في مجال

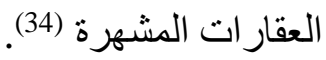

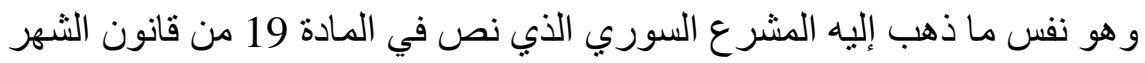

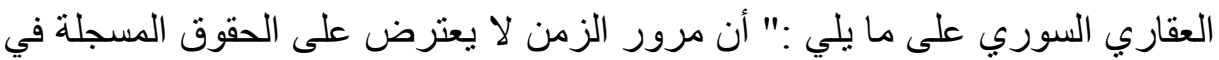

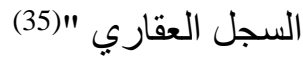
إلا أن المشرع الجزائري عند تبنيه لنظام الثهر العيني بموجب الأمر 74/75 


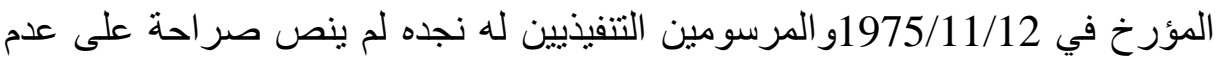

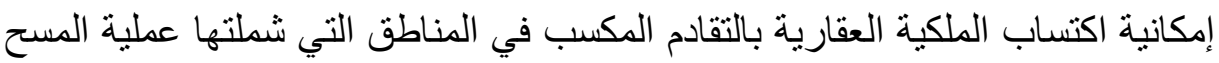
،إلا انه بالرجوع إلى القانون 02/07 المتضمن تأسيس إجراء لمعاينة حق الملكية

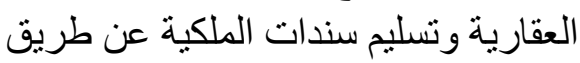
تحقيق عقاري ،حيث أجاز هذا الأخير في مادته 2 منه على إلى إكانية اكتساب الملكية

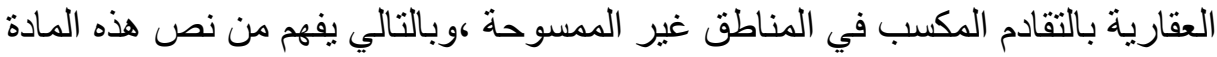

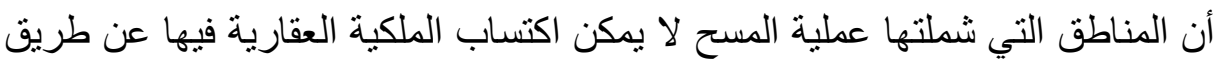

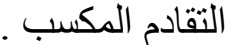

كما نجد أن المشرع الجز ائري نص في المادة 39 من قانون التوجيه العقاري على التى

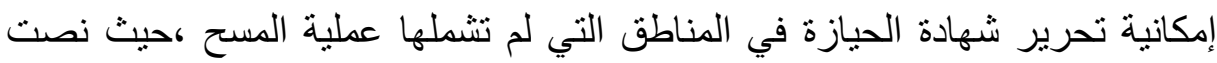
على ما يلي : "يمكن لكل شخص حسب مفهوم المادة 823 من الأمر رقم

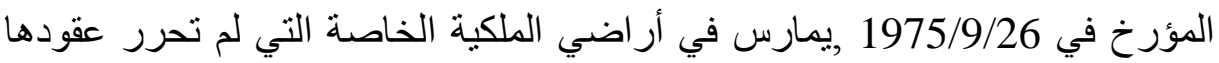

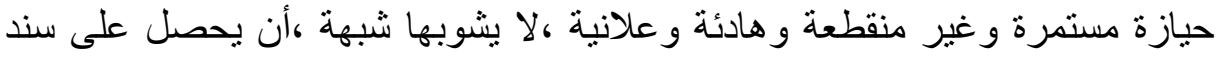

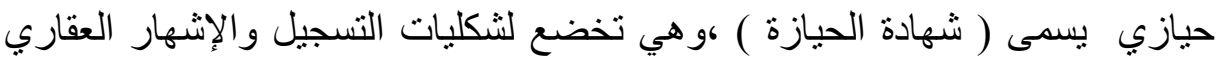

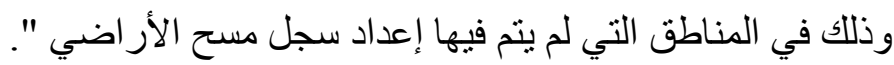

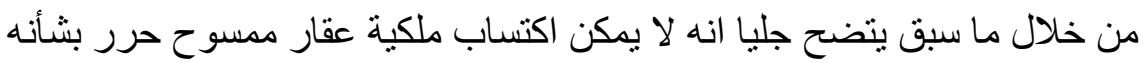

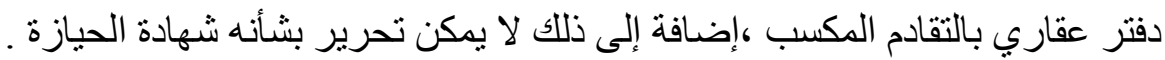
و عليه فان للافتر العقاري حجية قانونية مطلقة .

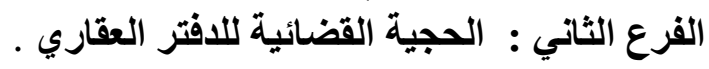

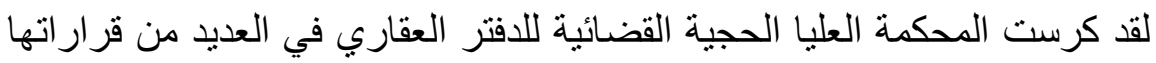

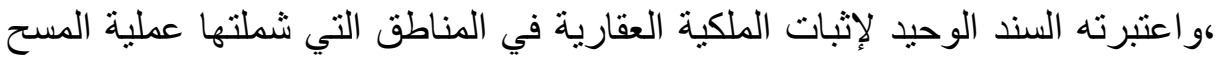

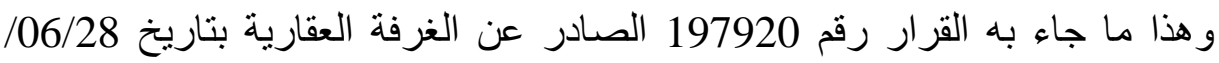

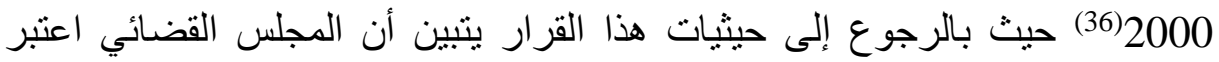

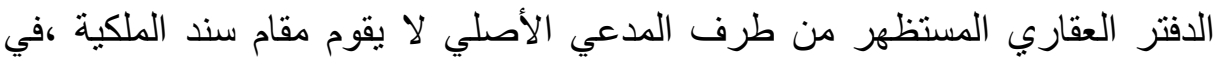
مقابل ذلك اعتبرت المحكمة العليا الدفتر العقاري السند الوحيد لإلثبات الملكية العقارية

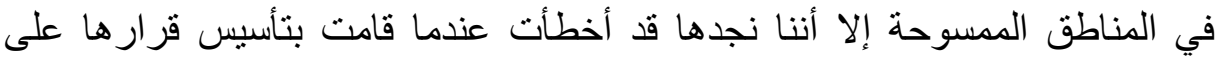

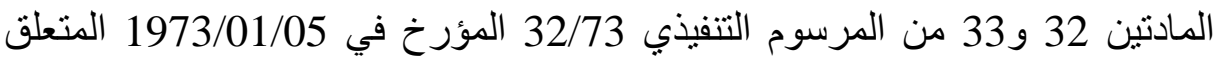

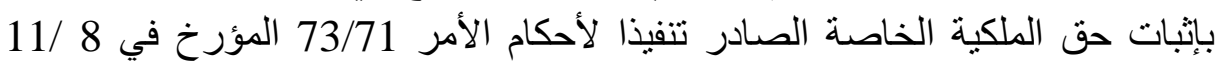

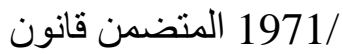

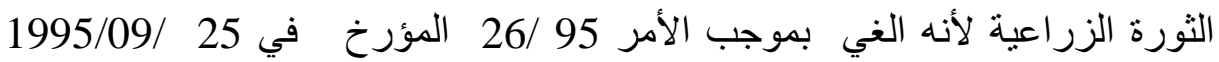

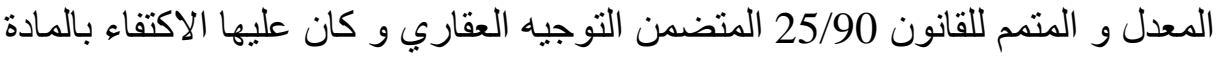

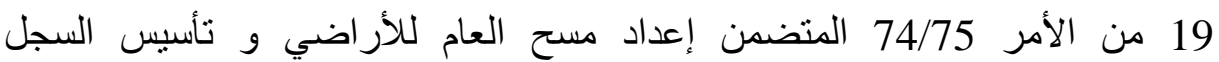

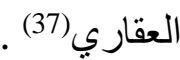

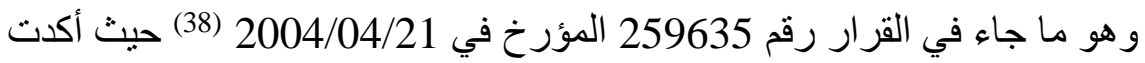
المحكمة العليا أن الدفتر العقاري يعتبر السند الأقوى لإثبات الملكية العقارية بالنسبة

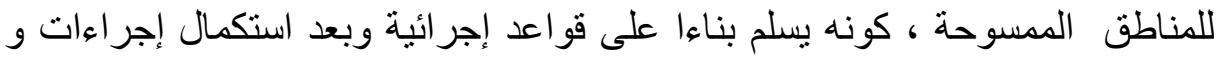

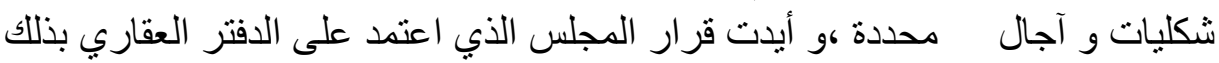

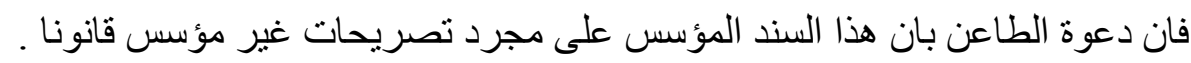


و القرار رقم 367715 المؤرخ في 15/ 11 / 2006 و الذي أكدت المحكمة العليا

من خلاله أن الدفتر العقاري هو سند إثبات الملكية العقارية إذا لم يقع الطعن فيه (39) .

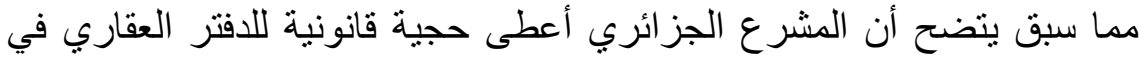

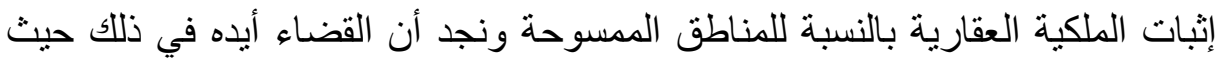

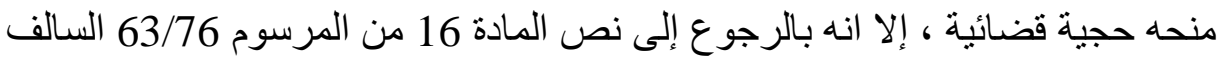

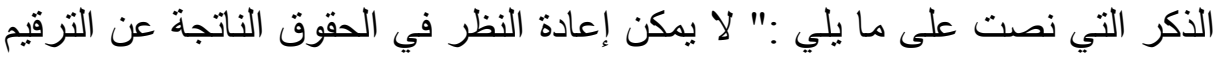
النهائي الذي نم بموجب أحكام المواد 12 و13و 14 من هذا الفصل إلإدي عن طريق القضاء " القياءي نجد أن المشرع الجزائري قد انقص من حجيته لأنه أعطى للأشخاص حق طعن في

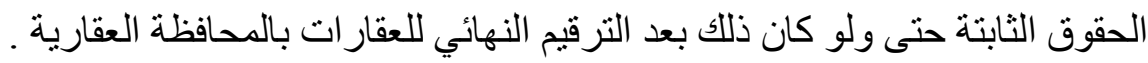

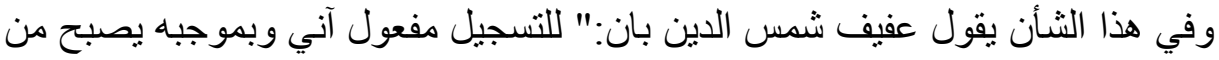

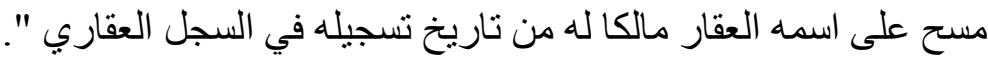

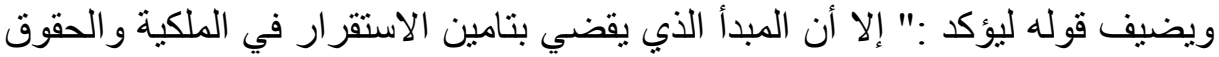

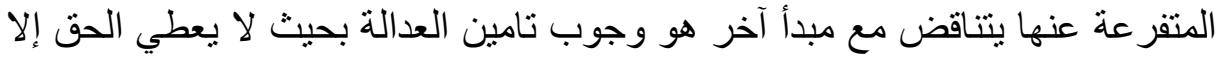

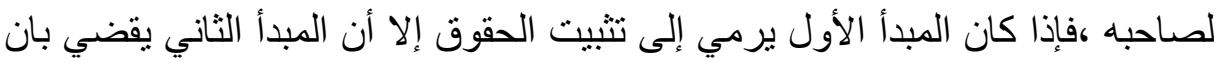
لا تكون عملية التحديد والتحرير رومن تم التسجيل في السجل العقاري ,وسيلة لهضم حقوق الآخرين وحرمانهم منها (40)".

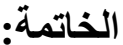

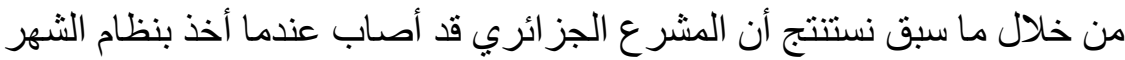

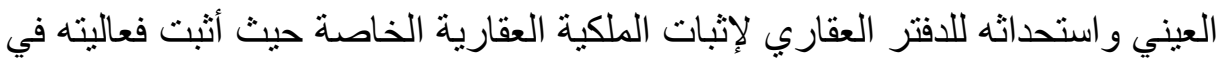
الإثبات وحماية حقوق الأشخاص من الاعتداءات التعسفية الصادرة عن الغير ،و يعتبر

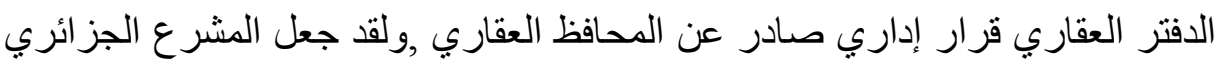

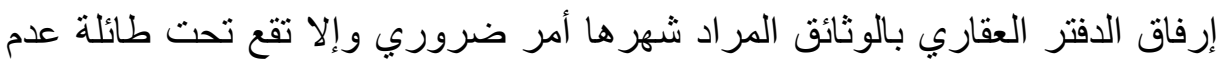

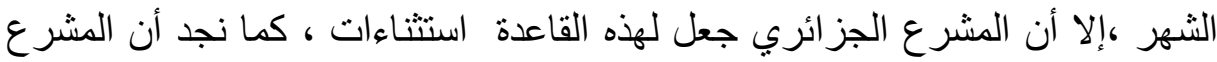

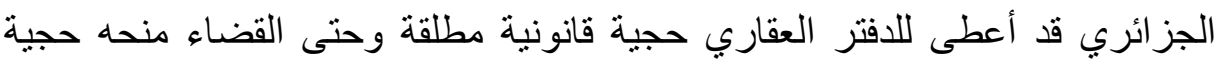

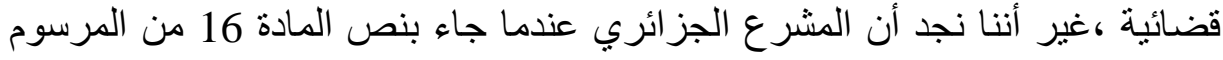

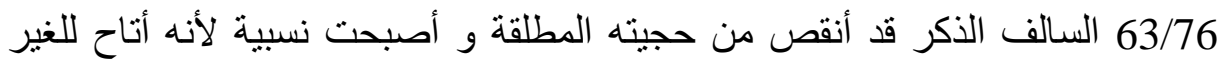

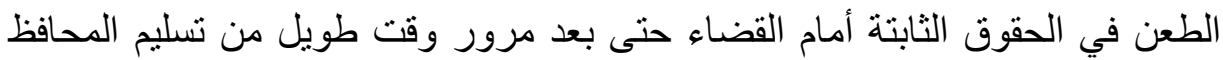

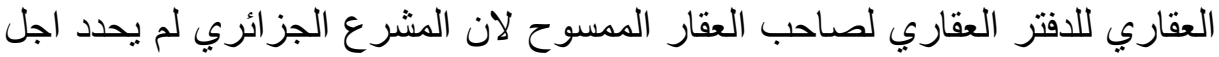

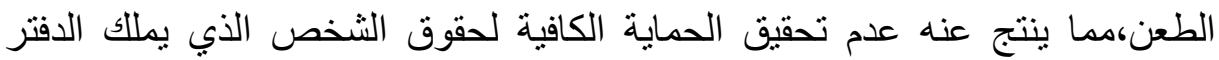

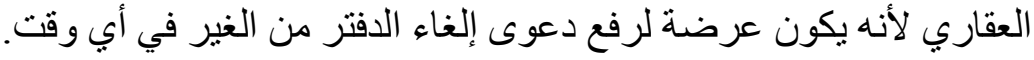

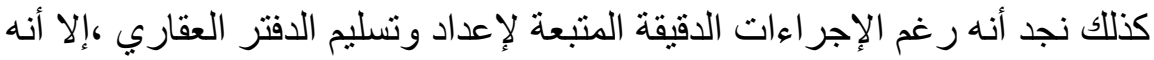

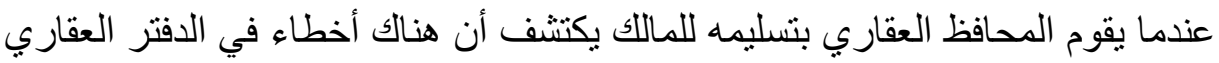
،وبالتالي فإن هذه الأخطاء قد تمس بمصداقية الدفتر العقاري. 
المراجـع

1- الأمر 74/75 المنضمن إعداد مسح الأر اضي العام وتأسبس السجل العقاري ،المؤرخ في

1975/11/12

جريدة رسمية ،العدد 92 و

2- المرسوم 62/76 المؤرخ في 1984/3/25 1976/24، ،المعدل والمتمم بالمرسوم التنفيذي رقم

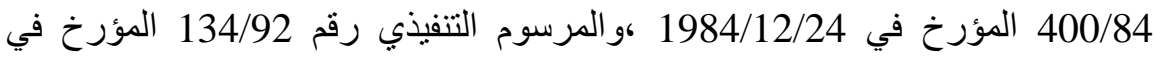

1992/4/7 ،المتضمن إعداد مسح الأر اضي العام ،الجريدة الرسمية ،العدد 30 ،المؤرخة

في 1976/4/13.

3- المرسوم 193/76 المؤرخ في 1976/3/25 ، المعدل والمتمم بالمرسومين التنفيذيين رقم

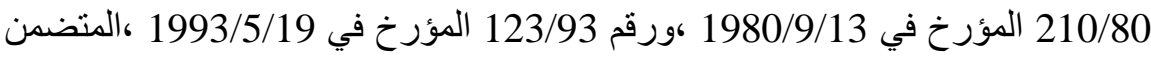

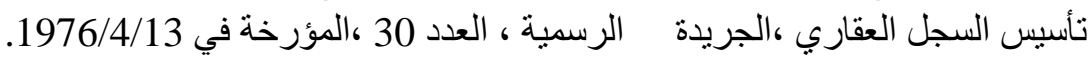

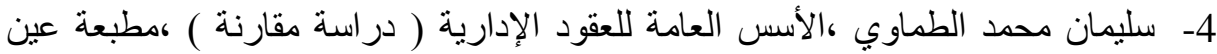

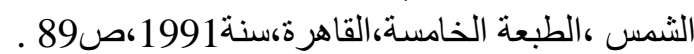

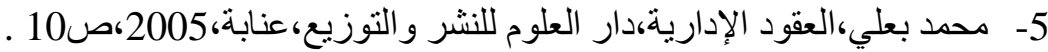

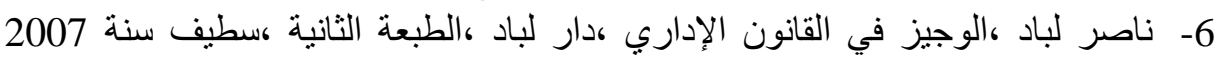

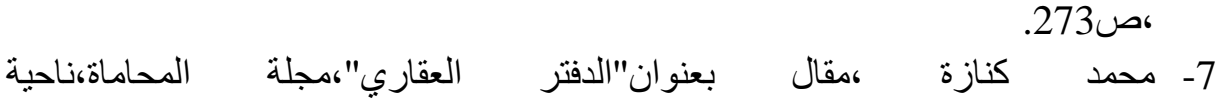

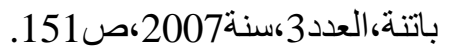

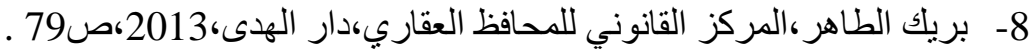

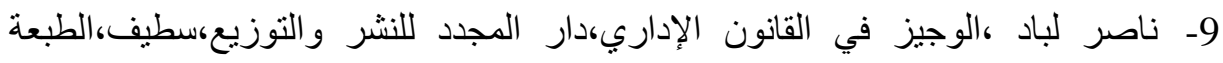

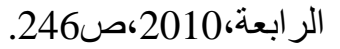

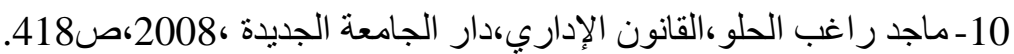

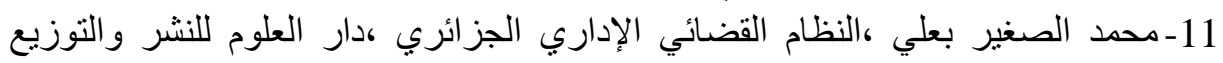

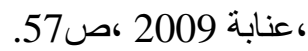

12- محمد فؤاد مهنا ،مبادئ وأحكام القانون الإداري في جمهورية مصر العربية ،القاهرة . 670 كاد 1973

13- عمار عوابدي ،نظرية القرارات الإدارية بين علم الإدارة والقانون الإداري ،دار هومة

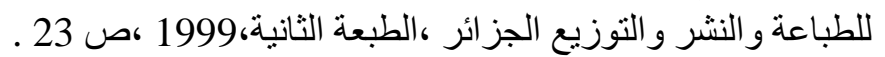

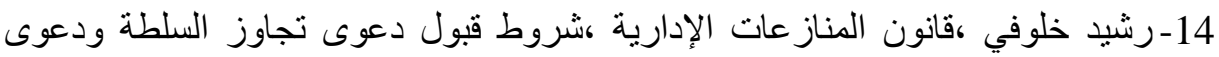

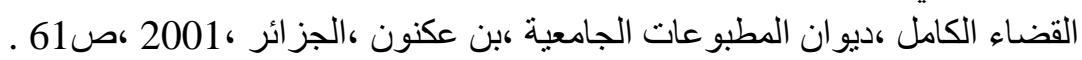

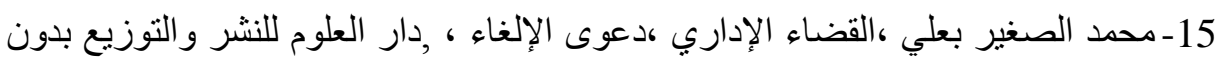

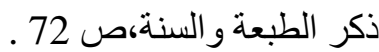

16- عمار بوضياف ،دعوى الإلغاء في قانون الإجر اءات المدنية والإدارية ،در اسة تشريعية

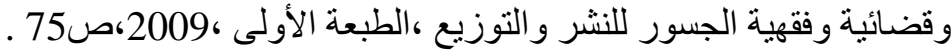

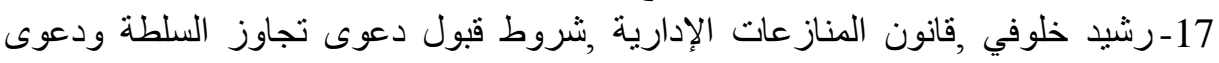
القضاء الكامل ,المرجع السابق ,ص صن 59.

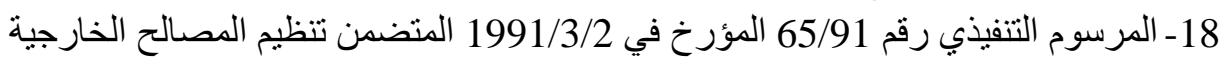

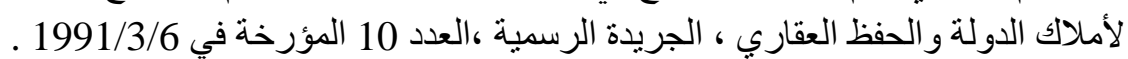


19-مانع جمال عبد الناصر ، مقال بعنوان " الاختصاص القضائي في إلغاء الدفاتر العقارية

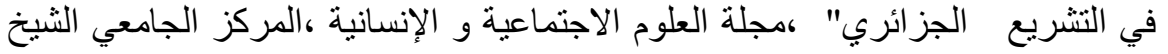

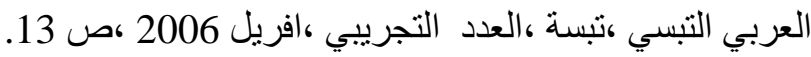

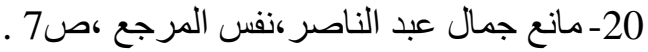

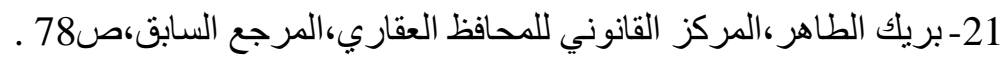

22- المادة 1 من القرار الوزاري المؤرخ في 1976/05/27 المنضمن تحديد نموذج الدفتر

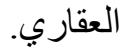

23- المادة45 من المرسوم 63/76 المعدل و المنمم.

24-رمول خالد، المحافظة العقارية كآلية للحفظ العقاري في التشريع الجزائري،قصر الكتراب الكتاب

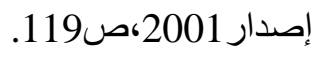

25-لياس بروك ،نظام الثهر العيني في الجزائر ،مذكرة ماجستير ،جامعة قاصدي مرباح

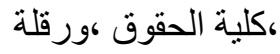

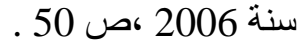

26-مجيد خلفوني ،نظام الثهر العقاري في القانون الجزائري ،دار هومه ،الطبعة الثانية . 2008 ، 208

27- المادة 50 من المرسوم 63/76 المؤرخ في المؤرخ في 1976/3/25 المتضمن تأسيس السجل العقاري.

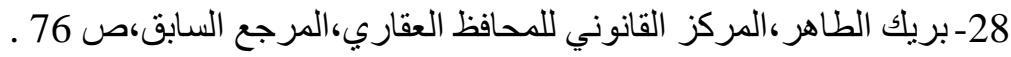

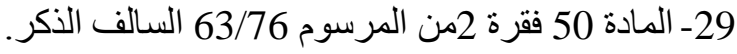

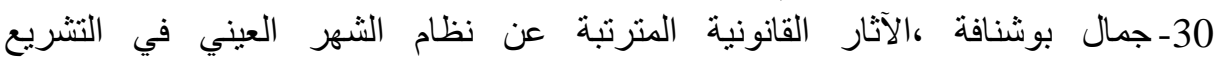

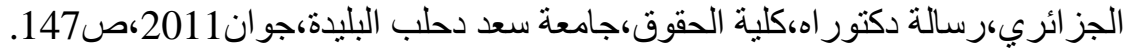

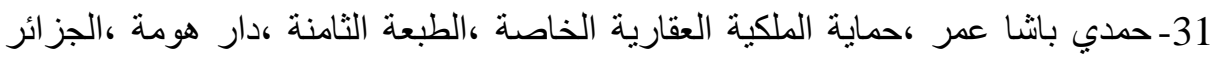

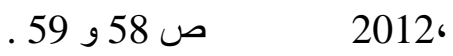

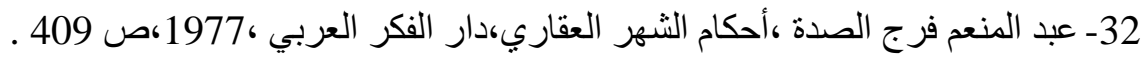

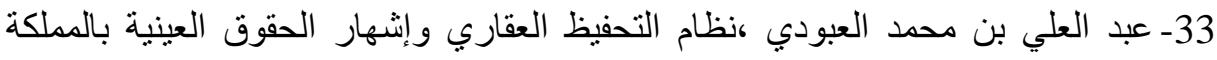

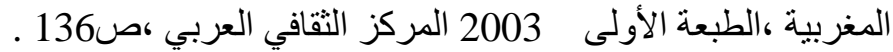

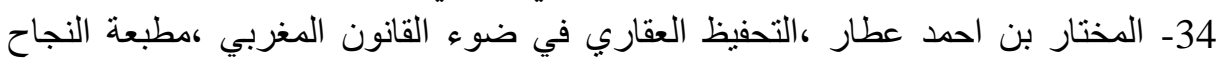

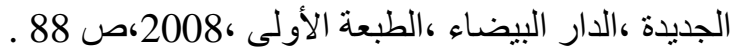

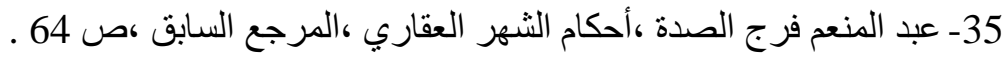

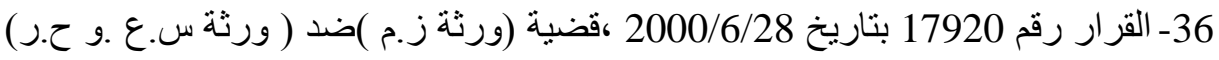

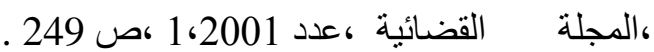

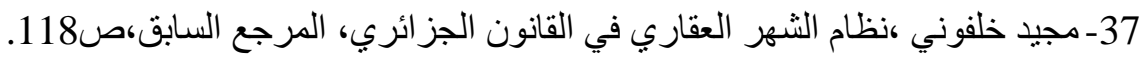
38- القرار رقم 259635 ،بتاريخ 20155 2004/4/21 ،قضية (ب.ر) ضد (ب.أ) ،المجلة القضائية

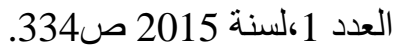

39- القرار رقم 367715 ،بتاريخ 334 2015 العد 2006/11/15 ،قضية (ي.ش.ح ) ضد (س.م) مجلة

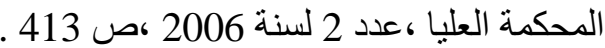

40- عفيف شمس الدين ،الوسيط في القانون العقاري ،الجزء الأول ،بيروت 1997 ، 116، (116، (10) 